Pacific Journal of Mathematics

A UNIQUENESS THEOREM FOR WEAK SOLUTIONS OF
SYMMETRIC QUASILINEAR HYPERBOLIC SYSTEMS 


\title{
A UNIQUENESS THEOREM FOR WEAK SOLUTIONS OF SYMMETRIC QUASILINEAR HYPERBOLIC SYSTEMS
}

\author{
A. E. HURD
}

The essentially bounded measurable (vector) function $u(x, t)=\left(u_{1}(x, t), \cdots, u_{r}(x, t)\right)$ is called a weak solution of the initial-value problem for the system

$$
\frac{\partial u}{\partial t}+\frac{\partial \mathscr{A}(x, t, u)}{\partial x}=0
$$

in the upper half-plane $t \geqq 0$ if it satisfies the usual integral identity (defining "weak") together with the condition that, given a compact set $D$ in $t \geqq 0$, there exists a function $K(t) \in L_{\mathrm{loc}}^{1}([0, \infty))$ such that

$$
\frac{u_{i}\left(x_{1}, t\right)-u_{\imath}\left(x_{2}, t\right)}{x_{1}-x_{2}} \leqq K(t)
$$

holds a.e. for $x_{1}, x_{2} \in D$ and $0<t<\infty$. It is shown that, if the matrix $\partial \mathscr{A} / \partial u$ is symmetric and positive definite (a convexity condition), then weak solutions are uniquely determined by their initial conditions.

In [1] O. A. Oleinik established a uniqueness theorem for a rather general class of weak solutions of a quasilinear equation of the form

$$
\frac{\partial u}{\partial t}+\frac{\partial \varphi(x, t, u)}{\partial x}+\psi(x, t, u)=0
$$

where the function $\varphi(x, t, u)$ was subject to a convexity condition in $u$, namely, $\varphi_{u u} \geqq 0$. The purpose of this note is to generalize Oleiniks uniqueness result (in the case $\psi \equiv 0$ ) to certain quasilinear systems which are subject to a symmetry condition (assumption III below) as well as a convexity condition (assumption IV below). In the case of one equation our uniqueness result is slightly less general than Oleiniks in that she does not require the function $K(t)$ occurring in (2) to be locally integrable on $[0, \infty)$. The method is the standard variation of Holmgren's method which is employed by Oleinik and others, except that we work with mean square rather than sup-norm estimates. Oleinik [2] has also established a uniqueness result for a special system of two equations which, however, is not symmetric. Rozhdestvenskii [3] has established a uniqueness theorem for piecewise smooth solutions of certain quasilinear systems but his methods are entirely different from those employed here.

2. In $D=\{(x, t):-\infty<x<\infty, 0 \leqq t<\infty\}$ we consider the quasi- 
linear system of $r$ equations

$$
\frac{\partial u}{\partial t}+\frac{\partial \mathscr{A}(x, t, u)}{\partial x}=0
$$

for the (vector) function $u(x, t)=\left(u_{1}(x, t), \cdots, u_{r}(x, t)\right)$ where

$$
\mathscr{A}(x, t, u)=\left(a_{1}(x, t, u), \cdots, a_{r}(x, t, u)\right) .
$$

The following assumptions will be made:

I. The functions $a_{i}(x, t, u)$ possess derivatives $\partial a_{i} / \partial u_{j}, \partial^{2} a_{i} / \partial x \partial u_{j}$ and $\partial^{2} a_{i} / \partial u_{j} \partial u_{k}$ which are bounded subsets of $(x, t, u)$-space.

II. Let

$$
\frac{\partial a_{i}(x, t, u)}{\partial u_{j}}=a_{i j}(x, t, u) .
$$

Then, if $u$ is bounded, i.e., $\sum u_{i}^{2} \leqq M^{2}$, there exists a constant $c$, depending only on $M$, such that

$$
-c \sum_{i=1}^{r} \xi_{i}^{2} \leqq \sum_{i, j=1}^{r} a_{i j}(x, t, u) \xi_{i} \xi_{j} \leqq c \sum_{i=1}^{r} \xi_{i}^{2}
$$

for all vectors $\xi=\left(\xi_{1}, \cdots, \xi_{r}\right)$.

III (Symmetry). For all $x, t$, and $u$,

$$
a_{i j}(x, t, u)=a_{j i}(x, t, u) \quad(i, j=1, \cdots, r)
$$

IV (Convexity). For all $x, t$, and $u$, and each $k=1, \cdots, r$, we have

$$
\sum_{i, j=1}^{r} \frac{\partial a_{i j}(x, t, u)}{\partial u_{k}} \xi_{i} \xi_{i} \geqq 0
$$

for all vectors $\xi=\left(\xi_{1}, \cdots, \xi_{r}\right)$.

DeFinition. Let $\psi(x)$ be an essentially bounded measurable function defined on $-\infty<x<\infty$. An essentially bounded measurable function $u(x, t)$ is called a weak solution of (1) in $D$ with initial conditions $\psi(x)$ if,

(a) for every test function $\varphi(x, t)$ which is continuously differentiable with compact support in the $(x, t)$-plane we have

$$
\int_{D}\left[\left\langle u, \frac{\partial \varphi}{\partial t}\right\rangle+\left\langle A(t, x, u), \frac{\partial \varphi}{\partial x}\right\rangle\right] d x d t+\int_{-\infty}^{\infty}\langle\varphi(x, 0), \psi(x)\rangle d x=0
$$

where $\langle$, $\rangle$ is the inner product in Euclidean $r$-space;

(b) given any compact subset of $D$ there is a corresponding function $K(t) \in L_{10 c}^{1}([0, \infty))$ such that 


$$
\frac{u_{i}\left(x_{1}, t\right)-u_{i}\left(x_{2}, t\right)}{x_{1}-x_{2}} \leqq K(t)
$$

$(i=1, \cdots, r)$ holds a.e. for $x_{1}$ and $x_{2}$ in the compact subset, and $0<t<\infty$.

Theorem. Weak solutions of (1) are uniquely determined by their initial conditions.

Proof. Let $u_{1}(x, t)$ and $u_{2}(x, t)$ be two weak solutions of (1) with the same initial conditions $\psi(x)$. We will show that, if $F(x, t)=$ $\left(F_{1}(x, t), \cdots, F_{r}(x, t)\right)$ is any smooth (vector) function with compact support contained in $t>0$, then

$$
\int_{D}\left\langle u_{1}-u_{2}, F\right\rangle d x d t=0
$$

thus proving that $u_{1}=u_{2}$ a.e. in $D$.

Let $\omega^{n}$ be the usual Gaussian averaging kernel with support contained in the sphere $x^{2}+t^{2} \leqq 1 / n^{2}$. Given a function $\varphi(x, t) \in L_{\mathrm{loc}}^{2}(D)$ we define the averaged function $\varphi^{n}(x, t)$ by convolution; $\varphi^{n}=\varphi * \omega^{n}$. By a familiar argument we see that $u_{i, k}^{n} \rightarrow u_{i k}(i=1,2$ and $k=1, \cdots, r)$ in mean square on compact subsets of $D$. From (3) it follows (see [1]) that

$$
\frac{\partial u_{i, k}^{n}}{\partial x} \leqq K(t) \quad(i=1,2 \text { and } k=1, \cdots, r)
$$

on compact subsets of $D$.

We now define the functions

$$
\begin{aligned}
& \alpha_{i j}(x, t)=\int_{0}^{1} \alpha_{i j}\left(x, t, \tau u_{1}+(1-\tau) u_{2}\right) d \tau \\
& \alpha_{i j}^{n}(x, t)=\int_{0}^{1} a_{i j}\left(x, t, \tau u_{1}^{n}+(1-\tau) u_{2}^{n}\right) d \tau
\end{aligned}
$$

$(i, j=1, \cdots, r$ and $n=1,2, \cdots)$ and the associated matrices $A(x, t)=$ $\left(\alpha_{i j}(x, t)\right)$ and $A^{n}(x, t)=\left(\alpha_{i j}^{n}(x, t)\right)$.

It is immediate that

$$
\mathscr{A}\left(x, t, u_{1}\right)-\mathscr{A}\left(x, t, u_{2}\right)=A(x, t)\left(u_{1}-u_{2}\right) \text {. }
$$

Also

$$
\left|a_{i j}^{n}(x, t)-\alpha_{i j}(x, t)\right| \leqq \text { const. }\left[\left|u_{1}^{n}-u_{1}\right|+\left|u_{2}^{n}-u_{2}\right|\right]
$$

on compact subsets of $D$, from which it follows that $a_{i j}^{n} \rightarrow \alpha_{i j}$ in mean square on compact subsets of $D$. From II we see that 


$$
-c\langle\xi, \xi\rangle \leqq\left\langle A^{n}(x, t) \xi, \xi\right\rangle \leqq c\langle\xi, \xi\rangle
$$

for some constant $c>0$ and all real vectors $\xi$. Finally we note that

$$
\begin{aligned}
\frac{\partial \alpha_{i j}^{n}}{\partial x} & =\int_{0}^{1}\left\{\frac{\partial a_{i j}}{\partial x}\left(x, t, \tau u_{1}^{n}+(1-\tau) u_{2}^{n}\right)\right. \\
& \left.+\sum_{k=1}^{r} \frac{\partial u_{i j}}{\partial u_{k}}\left(x, t, \tau u_{1}^{n}+(1-\tau) u_{2}^{n}\right)\left[\frac{\tau \partial u_{1, k}^{n}}{\partial x}+(1-\tau) \frac{\partial u_{2, k}^{n}}{\partial x}\right]\right\} d t .
\end{aligned}
$$

Using I, IV and (4) it follows that

$$
\left\langle\frac{\partial A^{n}}{\partial x} \xi, \xi\right\rangle \leqq K_{1}(t)\langle\xi, \xi\rangle
$$

on compact subsets of $D$ for every vector $\xi$, where $K_{1}(t) \in L_{1 \mathrm{loc}}^{1}([0, \infty))$.

We now construct for each $n=1,2, \cdots$ the vector function $\varphi^{n}(x, t)$ satisfying the linear system

$$
\frac{\partial \varphi^{n}}{\partial t}+A^{n}(x, t) \frac{\partial \varphi^{n}}{\partial x}=F(x, t)
$$

and vanishing on $t=T$, where the support of $F$ is assumed to be below $t=T$. This is achieved by solving the system

$$
\frac{\partial \widetilde{\varphi}^{n}}{\partial t}-A^{n}(x, T-t) \frac{\partial \widetilde{\varphi}^{n}}{\partial x}=F(x, T-t)
$$

for the vector function $\widetilde{\varphi}^{n}(x, t)$ in $D$, with the initial conditions $\widetilde{\varphi}^{n}(x, 0)=0$, and then putting $\varphi^{n}(x, t)=\widetilde{\varphi}(x, T-t)$. The classical existence theory guarantees that $\phi^{n}(x, t)$ exists, is smooth, and, by (5), has support contained in a compact set which is independent of $n$, and so is a legitimate test function.

Using (2) we obtain

$$
\begin{aligned}
\int_{D}\left\langle u_{1}-u_{2}, \frac{\partial \varphi^{n}}{\partial t}\right\rangle d x d t & =-\int\left\langle\mathscr{A}\left(x, t, u_{1}\right)-\mathscr{A}\left(x, t, u_{2}\right), \frac{\partial \varphi^{n}}{\partial x}\right\rangle d x d t \\
& =-\int_{D}\left\langle A(x, t)\left(u_{1}-u_{2}\right), \frac{\partial \varphi^{n}}{\partial x}\right\rangle d x d t
\end{aligned}
$$

Thus

$$
\int_{D}\left\langle u_{1}-u_{2}, F\right\rangle d x d t=\int_{D}\left\langle u_{1}-u_{2},\left(A^{n}-A\right) \frac{\partial \varphi^{n}}{\partial x}\right\rangle d x d t .
$$

Using the facts that (i) the supports of the $\varphi^{n}$ lie in a fixed compact subset of $D$, (ii) the $u_{i}$ are essentially bounded and (iii) the coefficients of $A^{n}$ converge in the mean square on compact subsets of $D$ to the coefficients of $A$, we see immediately that the right hand side of (6) approaches zero as $n \rightarrow \infty$, as long as the mean square norms of the 
$\partial \varphi_{i}^{r} / \partial x$ (on compact subsets of $D$ ) are uniformly bounded. The proof will be completed by establishing this fact.

Let $\partial \widetilde{\varphi}^{n} / \partial x=v^{n}, A^{n}(x, T-t)=\widetilde{A}^{n}(x, t)$ and $F(x, T-t)=\widetilde{F}(x, t)$. Then $v^{n}$ satisfies the equation

$$
\frac{\partial v^{n}}{\partial t}-\widetilde{A}^{n} \frac{\partial v^{n}}{\partial x}-\frac{\partial \widetilde{A}^{n}}{\partial x} v^{n}=\frac{\partial \widetilde{F}}{\partial x}
$$

in $0 \leqq t \leqq T$, and the initial conditions $v^{n}(x, 0)=0$. We may suppose that the supports of the $v^{n}(n=1,2, \cdots)$ in $0 \leqq t \leqq T$ are all strictly contained in some interval $a<x<b$. Then

$$
\frac{\partial}{\partial t}\left\langle v^{n}, v^{n}\right\rangle-\frac{\partial}{\partial x}\left\langle\widetilde{A}^{n} v^{n}, v^{n}\right\rangle=2\left\langle\frac{\partial \widetilde{F}}{\partial x}, v^{n}\right\rangle+\left\langle\frac{\partial \widetilde{A}^{n}}{\partial x} v^{n}, v^{n}\right\rangle .
$$

Using Green's formula

$$
\begin{gathered}
\int_{a}^{b}\left\langle v^{n}(x, t), v^{n}(x, t)\right\rangle d x \leqq \int_{0}^{t} \int_{a}^{b} 2\left\langle\frac{\partial \widetilde{F}}{\partial x}, v^{n}\right\rangle d x d t+\int_{0}^{t} \int_{a}^{b}\left\langle\frac{\partial \widetilde{A}^{n}}{\partial x} v^{n}, v^{n}\right\rangle d x d t \\
\leqq \int_{0}^{t} \int_{a}^{b}\left\langle\frac{\partial \widetilde{F}}{\partial x} \frac{\partial \widetilde{F}}{\partial x}\right\rangle d x d t+\int_{0}^{t}\left(1+K_{1}(s)\right)\left[\int_{a}^{b}\langle v(x, s), v(x, s)\rangle d x\right] d s
\end{gathered}
$$

from which it follows by Gronwall's Lemma that

$$
\int_{0}^{T} \int_{a}^{b}\left\langle v^{n}, v^{n}\right\rangle d x d t \leqq \text { constant }
$$

the constant depending on the $L^{2}$-norm of $\partial \widetilde{F} / \partial x$ and $\int_{0}^{T} K_{1}(t) d t$, but not on $n$. This completes the proof.

\section{BIBLIOGRAPHY}

1. O. A. Olěnik, Discontinuous solutions of non-linear differential equations, Uspehi Mat. Nauk (N.S.) 12 (1957), no. 3 (75), 3-73 (Amer. Math. Soc. Translations, Series 2, Vol. 26, 95-172.)

2. - On the uniqueness of the generalized solution of the Cauchy problem for a nonlinear system of equations occurring in mechanics, Uspehi Mat. Nauk (N.S.) 12 (1957), no. 6 (78), 169-176.

3. B. L. Rozhdestvenskii, Discontinuous solutions of hyperbolic systems of quasilinear equations, Russian Math Surveys 15 (1960), 53-111.

Received April 10, 1967, and in revised from May 28, 1968. The preparation of this paper was sponsored in part by NSF Grant GP-5279.

University of California, Los ANGeles 



\section{PACIFIC JOURNAL OF MATHEMATICS}

\section{EDITORS}

\author{
H. ROYDEN \\ Stanford University \\ Stanford, California \\ R. R Phelps \\ University of Washington \\ Seattle, Washington 98105
}

\author{
J. Dugundui \\ Department of Mathematics \\ University of Southern California \\ Los Angeles, California 90007
}

RICHARD ARENS

University of California

Los Angeles, California 90024

\section{ASSOCIATE EDITORS}
E. F. BeCKENBACH
B. H. NeUmanN
F. WolF
K. YosidA

\section{SUPPORTING INSTITUTIONS}

\author{
UNIVERSITY OF BRITISH COLUMBIA \\ CALIFORNIA INSTITUTE OF TECHNOLOGY \\ UNIVERSITY OF CALIFORNIA \\ MONTANA STATE UNIVERSITY \\ UNIVERSITY OF NEVADA \\ NEW MEXICO STATE UNIVERSITY \\ OREGON STATE UNIVERSITY \\ UNIVERSITY OF OREGON \\ OSAKA UNIVERSITY \\ UNIVERSITY OF SOUTHERN CALIFORNIA
}

\author{
STANFORD UNIVERSITY \\ UNIVERSITY OF TOKYO \\ UNIVERSITY OF UTAH \\ WASHINGTON STATE UNIVERSITY \\ UNIVERSITY OF WASHINGTON

$* * * * *$
AMERICAN MATHEMATICAL SOCIETY
CHEVRON RESEARCH CORPORATION
TRW SYSTEMS
NAVAL WEAPONS CENTER

The Supporting Institutions listed above contribute to the cost of publication of this Journal, but they are not owners or publishers and have no responsibility for its content or policies.

Mathematical papers intended for publication in the Pacific Journal of Mathematics should be in typed form or offset-reproduced, double spaced with large margins. Underline Greek letters in red, German in green, and script in blue. The first paragraph or two must be capable of being used separately as a synopsis of the entire paper. It should not contain references to the bibliography. Manuscripts, in duplicate if possible, may be sent to any one of the four editors. Please classify according to the scheme of Math. Rev. 36, 1539-1546. All other communications to the editors should be addressed to the managing editor, Richard Arens, University of California, Los Angeles, California, 90024.

50 reprints are provided free for each article; additional copies may be obtained at cost in multiples of 50 .

The Pacific Journal of Mathematics is published monthly. Effective with Volume 16 the price per volume (3 numbers) is $\$ 8.00$; single issues, $\$ 3.00$. Special price for current issues to individual faculty members of supporting institutions and to individual members of the American Mathematical Society: $\$ 4.00$ per volume; single issues $\$ 1.50$. Back numbers are available.

Subscriptions, orders for back numbers, and changes of address should be sent to Pacific Journal of Mathematics, 103 Highland Boulevard, Berkeley, California, 94708.

PUBLISHED BY PACIFIC JOURNAL OF MATHEMATICS, A NON-PROFIT CORPORATION

Printed at Kokusai Bunken Insatsusha (International Academic Printing Co., Ltd.), 7-17. Fujimi 2-chome, Chiyoda-ku, Tokyo, Japan. 


\section{Pacific Journal of Mathematics}

Vol. 28, No. 3

May, 1969

Jon F. Carlson, Automorphisms of groups of similitudes over $F_{3} \ldots \ldots \ldots$

W. Wistar (William) Comfort, Neil Hindman and Stelios A. Negrepontis,

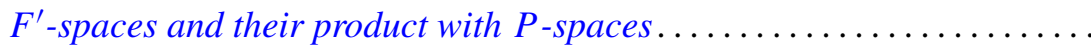

Archie Gail Gibson, Triples of operator-valued functions related to the unit

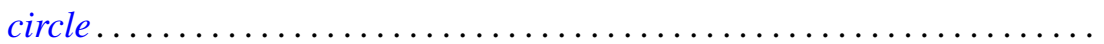

David Saul Gillman, Free curves in $E^{3}$

E. A. Heard and James Howard Wells, An interpolation problem for

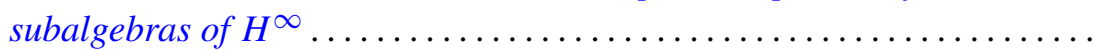

Albert Emerson Hurd, A uniqueness theorem for weak solutions of symmetric

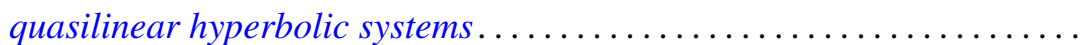

E. W. Johnson and J. P. Lediaev, Representable distributive Noether

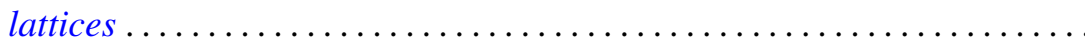

David G. Kendall, Incidence matrices, interval graphs and seriation in

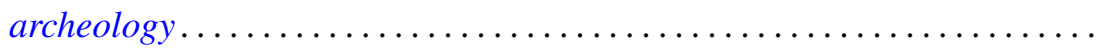
565

Robert Leroy Kruse, On the join of subnormal elements in a lattice ....... 571

D. B. Lahiri, Some restricted partition functions; Congruences modulo 3 .... 575

Norman D. Lane and Kamla Devi Singh, Strong cyclic, parabolic and conical differentiability........................................

William Franklin Lucas, Games with unique solutions that are

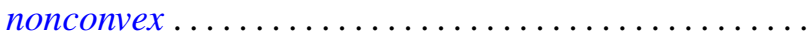

Eugene A. Maier, Representation of real numbers by generalized geometric series.

Daniel Paul Maki, A note on recursively defined orthogonal polynomials ...

Mark Mandelker, $F^{\prime}$-spaces and z-embedded subspaces ...

James R. McLaughlin and Justin Jesse Price, Comparison of Haar series with gaps with trigonometric series

Ernest A. Michael and A. H. Stone, Quotients of the space of irrationals ....

William H. Mills and Neal Zierler, On a conjecture of Golomb ...

J. N. Pandey, An extension of Haimo's form of Hankel convolutions ...

Terence John Reed, On the boundary correspondence of quasiconformal mappings of domains bounded by quasicircles...

Haskell Paul Rosenthal, A characterization of the linear sets satisfying Herz's criterion.

George Thomas Sallee, The maximal set of constant width in a lattice...

I. H. Sheth, On normaloid operators

James D. Stasheff, Torsion in BBSO ...

Billy Joe Thorne, A - P congruences on Baer semigroups.

Robert Breckenridge Warfield, Jr., Purity and algebraic compactness for

modules... 